\title{
Peer reviewed journals, science and social justice
}

\section{Ruth E Malone}

For the last 2 years, Tobacco Control has benefited from opportunities to enhance connections with authors and potential authors from low/middle income countries (LMICs), through a special grant provided by the Bloomberg Foundation. The grant, based on a proposal initiated by Editor Emeritus Simon Chapman, provided funding for several LMIC introductory workshops on writing for the journal, additional open-access pages in the journal devoted to papers and news from LMICs, and increased editorial support and mentoring for authors with good ideas but little or no experience in writing for a peer reviewed journal. More than 100 participants from LMICs attended our workshops, we published over 200 additional pages of LMIC news, research papers, advocacy pieces and other contributions, and more than a dozen authors received individual mentoring help with papers, eventually leading to successful publications.

However, an unanticipated side effect of these LMIC-focused initiatives has been the interesting conversations they have stimulated among the senior editors of the journal, and the ways in which they have expanded our perspectives on our roles as editors and mediators of discourse in a field where both science and social justice are at issue.

For example, at a recent editorial team meeting, we discussed a research paper from a LMIC author. The science was well done and with a little editing for English, the paper was potentially publishable. But should we send it out for review? The question we were wrestling with was whether its findings were sufficiently new to make it worthy of page space in the journal. This is always a consideration for all manuscripts, since competition for space is intense and a priority is to publish interesting research that adds something new to the field, rather than too many replications of studies already done. So the initial response when deciding whether to

Correspondence to Dr Ruth E Malone, Professor of Nursing and Health Policy, Department of Social and Behavioral Sciences, University of California, San Francisco, CA 94118, USA; ruth.malone@ucsf.edu send the paper out for peer review was: Reject. We already know this, don't we?

However, as we continued the discussion, we acknowledged that the previous studies on the same topic had almost all been conducted in high income countries. As we discussed the paper's strengths and weaknesses, we began to talk about what an achievement it was for these authors to have completed this study in a country with so few resources, while facing other obstacles such as an unstable government and inadequate information technology support. And this led to a thoughtprovoking discussion on the role of journals as instruments of communication that can play a modest role in either reducing or perpetuating global social inequities.

LMIC tobacco control communities are already socially disadvantaged by having fewer monetary resources, less government infrastructure to support public health research, policies and programmes, and fewer scientists well-prepared to conduct rigorous studies. Now, thanks to increasing global interest in stemming the global tobacco disease epidemic, some resources are finally flowing to these countries to fund the types of research that scientists in higher income countries were able to do years ago (though these research resources are still not proportional to the scale of the tobacco problem these countries are facing, nor to resources for research on other types of disease epidemics). For many years, researchers residing in low income countries could not do the work for lack of resources. To now deny publication of high quality work because similar studies were already done in wealthier countries simply compounds their existing structural disadvantage.

The impact of a high-profile journal publication of work conducted in a LMIC can be certainly profound, drawing additional media attention to policy initiatives and programmes. It can help national and even local policymakers become aware that the international community is interested in their actions (or their failure to act) to protect public health. Such international attention to a well-done study in one's own country can spur leadership or spotlight its absence. In the 'real world' of tobacco control on the ground, such a publication may be of more immediate practical use than several studies from wealthier countries.

It is also important to consider whether these are really such similar studies after all, given the vastly different contexts. Two studies of the effects of a new smokefree law, for example, while nominally reporting similar findings, may mean something quite different in Lagos than they do in Los Angeles. The regulatory climate of each city, the demographics of their tobacco-using populations, public awareness of the policy, the presence or absence of multinational tobacco company influences, and numerous other factors, while perhaps not directly affecting the measures used in the study, do affect interpretations of what it means.

No journal can afford to devote all or even most of its precious page space to studies essentially finding again what others already found, with only the places changing. And this may be a good place to remind authors that we almost never publish prevalence studies, unless they are truly the first ever done (and sometimes not even then), since they tend to be of interest primarily in the countries within which they were conducted. But despite lingering positivist assumptions, science is not now nor has it ever been a value-free enterprise. The art of journal editing is likewise fraught with ethical considerations that extend beyond those concerned with human subjects and authorship criteria, to name but two common ethical issues with which editors must be concerned. In a globalised world, these ought to also include consideration of both the relative advantages enjoyed by some authors and the lessons less-privileged colleagues can teach the more affluent about how to persevere, how to prevent and how to do more with less than most of us can imagine.

We are proud of our track record in publishing work from LMICs, and we look forward to meeting more future authors from these countries at the upcoming World Conference on Tobacco or Health in Singapore 20-24 March 2012. But there is much more to be done. If we are serious about tackling tobacco as a social justice issue, we have to consider how to bring even more voices from LMICs to the dialogues. We welcome your ideas!

\section{Competing interests None.}

Provenance and peer review Commissioned; internally peer reviewed.

Tobacco Control 2012;21:1

doi:10.1136/tobaccocontrol-2011-050321 